The contribution of small accommodations to a sustainable tourism industry

\author{
$\underline{\text { Najmeh Hassanli }}$ \\ University of Technology Sydney \\ PO Box 123 Broadway NSW 2007 Australia \\ +61295144168
}

$\underline{\text { Najmeh.hassanli@uts.edu.au }}$

LinkedIn: https://www.linkedin.com/in/najmeh-hassanli-4b195464/

ORCiD ID: 0000-0002-8421-3892

\author{
Janine Ashwell \\ Le Cordon Bleu \\ Days Road, Regency Park, SA 5010 \\ +61883483036 \\ jashwell@cordonbleu.edu \\ LinkedIn: https://www.linkedin.com/in/drjanineashwell-71282a9a
}

ORCiD ID: 0000-0003-0779-9575 


\title{
The contribution of small accommodations to a sustainable tourism industry
}

\begin{abstract}
Given the central role of small accommodations to the tourism industry in Australia, this study investigated the drivers and challenges of small accommodation providers (SAPs) to engage in sustainability practices. In-depth interviews were undertaken with accommodation providers in the wine region of McLaren Vale in South Australia. The main drivers in implementing sustainability were identified as cost reduction competitiveness, societal legitimisation and lifestyle-values. Key challenges included personal, financial and operational. Moreover, SAPs identified an opportunity to influence guests' sustainable behaviour, but their limited knowledge and a concern for a negative impact on guest experience prevented them from implementing relevant strategies. This research letter contributes to the literature on small accommodation lodgings, and provides practical recommendations to local agencies wanting to support small accommodations in implementing sustainable practices.
\end{abstract}

\section{Key words}

Small accommodation lodgings; sustainable practices; sustainable tourism; drivers; challenges 
Comparable to other industries, the tourism industry, which is reliant on the quality of natural, built and cultural environment for its continued viability (Hobson \& Essex, 2001), is under increasing pressure to develop sustainability initiatives (Camilleri, 2014). Seen as the application of the sustainable development idea to the tourism industry, sustainable tourism is based on the three pillars of economic, socio-cultural and environmental assessments (Bramwell \& Bernard, 2011). Whilst progress has been made in the field of sustainable tourism research, it is commonly related to theories and concepts (Camilleri, 2014) or focuses mainly on large firms (Garay \& Font, 2012; Thomas, Shaw, \& Page, 2011). This contradicts the nature of tourism industry being mainly dominated by small- and medium-sized enterprises (SMEs) (Font, Garay, \& Jones, 2016; Morrison, Carlsen, \& Weber, 2010).

Small accommodation lodgings have the potential to contribute to the sustainability objectives of the tourism destinations within which they are located (Morrison et al., 2010). Despite the central role of the small accommodation sector to the Australian tourism industry (Hall et al., 2016; Kookana \& Quinn, 2013), limited research has been undertaken into the sustainable practices of small accommodation providers (SAPs) (Hall et al., 2016). The majority of such studies have considered issues associated with environmental sustainability, including influencing guest behavior (e.g. Borden, Coles, \& Shaw, 2017), with less research undertaken on issues associated with social and economic sustainability (Melissen, 2013). To overcome the gap in the literature, this research letter reports a study which investigated Australian SAPs' drivers and challenges to engage in sustainability practices.

Within the broader tourism SME literature, drivers and challenges to engage in sustainable practices have been identified. Such drivers are categorized as: cost reduction competitiveness with proprietors implementing measures which provide financial benefits or a competitive advantage; societal legitimisation where actions expected by others are implemented, and lifestyle-value drivers which reflect personal values (Font et al., 2016; Garay \& Font, 2012). 
Literature also explores challenges faced by tourism SMEs, including small accommodations, in their commitment to sustainability. According to studies in Europe, the negative impact that sustainable initiatives could have on guest satisfaction, acts as a primary challenge for small accommodations (Borden et al., 2017). Sustainable development initiatives are also a source of cost for the providers; requiring additional investment of time, energy and finances as well as information and expertise (Borden et al., 2017; Garay \& Font, 2012; Melisson, Koens, Brinkman, \& Smit, 2016).

To understand the key drivers and challenges of SAPs in Australia, the study applied an interpretive and qualitative research approach. In-depth interviews were conducted with 11 SAPs who were members of a B\&B owners group based in McLaren Vale, a regional wine tourism destination in South Australia. Purposive sampling was applied, with attendees at the B\&B owners group annual meeting invited to participate in the study. Theoretical saturation was used to determine the sample size. A total of 8 interviews were conducted; a third of which were dyadic interviews with married couples who jointly ran the accommodation, thus adding to the depth and richness of data (Morgan, Ataie, Carder, \& Hoffman, 2013). Gender distribution was fairly even across the respondents and the length of operation varied from less than 1 year to 9 years (Table 1). Congruent with an Australian industry report (Cloutman, 2016), only one property was a primary source of income, with five properties operated as a secondary source of income to support SAPs' change of lifestyle.

In order not to pressurize respondents, the opening interview question was framed as a broad starting point (Rao \& Perry, 2003), focusing on SAPs' understanding of sustainable tourism and examining their sustainable practices using the three pillars of sustainability as a framework. Further probing questions were used to examine drivers behind positive practices and challenges to implement further changes. Following each interview, details of the setting and observations were recorded. This helped to provide context to the interviews at the analysis 
stage, with observation notes compared to and contrasted with interview transcripts to check the consistency of information (Patton, 2002). Data was coded and analysed using NVivo11.

\begin{tabular}{|c|c|c|c|c|c|c|}
\hline 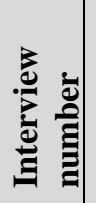 & 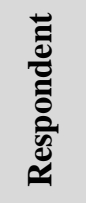 & 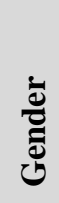 & $\begin{array}{c}\text { Main source } \\
\text { of income }\end{array}$ & Reside on premises & Accommodation type &  \\
\hline \multirow[t]{2}{*}{1} & $\mathrm{R} 1$ & $\mathrm{M}$ & \multirow[t]{2}{*}{ No } & \multirow[t]{2}{*}{ No } & \multirow[t]{2}{*}{$\mathrm{B} \& \mathrm{~B}$} & \multirow[t]{2}{*}{3 years } \\
\hline & R2 & $F$ & & & & \\
\hline 2 & R3 & $\mathrm{M}$ & Yes & No, but on site & Self-catering & 1 year \\
\hline 3 & R4 & $\mathrm{F}$ & No, Retired & Yes, within home & $\mathrm{B} \& \mathrm{~B}$ & $<1$ year \\
\hline \multirow[t]{2}{*}{4} & R5 & $\mathrm{M}$ & \multirow{2}{*}{ No } & \multirow{2}{*}{ No, but on site } & \multirow[t]{2}{*}{$\mathrm{B} \& \mathrm{~B}$} & \multirow{2}{*}{$<1$ year } \\
\hline & R6 & $\mathrm{F}$ & & & & \\
\hline 5 & R7 & $\mathrm{F}$ & No, Retired & No, but on site & $\mathrm{B} \& \mathrm{~B}$ & 9 years \\
\hline \multirow[t]{2}{*}{6} & $\mathrm{R} 8$ & $\mathrm{M}$ & \multirow{2}{*}{ No } & \multirow{2}{*}{ No, but on site } & \multirow[t]{2}{*}{ Self-catering } & \multirow{2}{*}{$<1$ year } \\
\hline & R9 & $\mathrm{F}$ & & & & \\
\hline 7 & R10 & $\mathrm{M}$ & No & Yes, within home & $\mathrm{B} \& \mathrm{~B}$ & 4 years \\
\hline 8 & R11 & $\mathrm{M}$ & No & No, but on site & $\mathrm{B} \& \mathrm{~B}$ & 8 years \\
\hline
\end{tabular}

Table 1: Respondents' profile

In relation to SAPs' understanding of the term sustainable tourism, respondents had limited knowledge; with the majority associating the term with environmental and economic impacts. Their lack of understanding could be associated with only a limited number of SAPs having prior tourism industry experience; R3 had been a senior executive in the industry, whilst R4 had previously operated a small accommodation lodging. Despite three of the respondents not having any understanding of the term sustainable tourism, they were still engaged in sustainable practices, as discussed below. This finding supports previous studies that small businesses do not self-identify as behaving sustainability even when engaged in a range of triple bottom line activities (Collins, Dickie, \& Weber, 2009).

The interview data identified a number of sustainable practices employed by SAPs. These included applying water restrictors in showers; utilising solar power; employing environmentally-friendly cleaning fluids; and recycling waste. SAPs had also given consideration to environmental impacts when renovating properties by using local resources 
and recycled materials. Similarly, practices connected to economic sustainability were discussed; with SAPs highlighting the importance of their role in attracting tourists to the area and encouraging them to extend their stay. The respondents also emphasised their role in recommending local experiences (e.g. wineries).Yet, the complexity of achieving economic benefits without damaging the environment was clearly summarized by a respondent, who identified that improving access to the area by increasing infrastructure such as roads can 'actually kill the value proposition that you have for the area' (R3).

Despite respondents not including social impacts in their definition of sustainable tourism, practices were identified during data analysis which aligned with social sustainability. Consistent with McLaren Vale's destination image, respondents had a strong focus on using local food to strengthen the region's identity and sustain its heritage. Furthermore, to reduce the impact of drink driving on the host community, alternative transport options were provided. Whilst respondents acknowledged the increased impact of visitor numbers on the community in terms of traffic, especially on the weekends, they felt this brought benefits such as keeping local businesses open. Nevertheless, in an attempt to reduce the impact of traffic, SAPs discussed the benefit of providing guests with access to bicycles.

To understand how to further engage SAPs in sustainable practices, the study identified drivers and challenges to participation. Comparable to SMEs in other sectors of the tourism industry, SAPs' drivers to implement sustainable practices were not homogenous (Font et al., 2016). Cost reduction competitiveness was identified as a driver, with sustainable practises implemented to create a competitive advantage through differentiation. When discussing the relevance of implementing sustainable practices R5 noted 'it gives us a point of difference and it might be a talking point that gets people to come back and visit us as well, so it benefits both'. Likewise, R3 saw the benefits of implementing environmentally sustainable practices as a differentiator on Trip Advisor. Societal legitimisation was also evident within the interviews, 
with implemented practices reflecting SAPs' intention to become embedded within the community by applying the values of the local community. As noted by one respondent: '...there's a very strong focus in the community...for recycling sustainable materials and valuing that sort of thing. So I guess that raised the focus with us a bit more to use that sort of thing as well...' (R1). Finally, practices such as recycling that were employed by SAPs in their own homes were also replicated in their business to reinforce lifestyle-value drivers. Once respondent stated: 'We've always been quite conscious of recycling... I mean I wouldn't say by any stretch we're environmentalists, don't get me wrong, but we try and do what we can' (R4).

Challenges in implementing additional sustainability practices were themed as operational, personal and financial. Operational challenges included guest satisfaction and council restrictions on altering heritage buildings. As reported in other studies (Borden et al., 2017) guest satisfaction was identified as a primary challenge, which was in conflict with many of the SAPs' lifestyle-value drivers. Rather than pressurising guests into recycling waste, half of the respondents resorted to separating guests' wastes themselves. According to one respondent: '... We give the guests the option, but...they either don't obey the rules or they don't bother. So we do a lot of the sorting' (R8). This further influenced SAPs' personal challenge of increased workload and shortage of time. Respondents also highlighted that a lack of knowledge had a significant influence on their capacity to implement further sustainable practices. The final theme financial, included challenges connected to increased costs and lack of ROI, which supported findings in other contexts (Borden et al., 2017; Garay \& Font, 2012; Melisson et al., 2016). To assist SAPs in addressing their identified challenges, local support agencies may disseminate 'Best Practice' found within the literature via resources such as leaflets, websites or workshops. Local governments may also provide financial support in the form of grants or rebates to encourage practices such as energy saving and waste reduction. 
While this study supports previous findings in the literature, it also identified SAPs' recognition of their opportunity to influence guests' sustainable behaviour. However, as a consequence of their lack of knowledge, and focus on guest experience, none had implemented practices to support this. Hence, building on recent research (see Borden et al., 2017), future studies could employ Social Marketing principles to identify ways to engage guests in sustainable practices. To overcome SAPs' limited knowledge and contribute to the gap in the small accommodation literature, future research could focus on socio-economic sustainability.

The low sample size and geographical limitation prevent generalisation of findings of this research. Nevertheless, this exploratory study has contributed to the limited literature on Australian small accommodation sector (Hall et al., 2016) identifying SAPs drivers and challenges in implementing sustainable practices and new avenues for future research.

\section{References}

Borden, D. S., Coles, T., \& Shaw, G. (2017). Social marketing, sustainable tourism, and small/medium size tourism enterprises: challenges and opportunities for changing guest behaviour. Journal of Sustainable Tourism, 25(7), 903-920.

Bramwell, B., \& Bernard, L. (2011). Critical research on the governance of tourism and sustainability. Journal of Sustainable Tourism, 19(4-5), 411-421.

Camilleri, M. (2014). Advancing the sustainable tourism agenda through strategic CSR perspectives. Tourism Planning \& Development, 11(1), 42-56.

Cloutman, N. (2016). Bed and Breakfast Accommodation in Australia (OD5376). Retrieved from IBISWorld: $\quad$ https://www.ibisworld.com.au/industry-trends/specialised-market-researchreports/consumer-goods-services/bed-breakfast-accommodation.html

Collins, E., Dickie, C., \& Weber, P. (2009). A New Zealand and Australian overview of ethics and sustainability in SMEs. African Journal of Business Ethics, 4(2), 48-55.

Font, X., Garay, L., \& Jones, S. (2016). Sustainability motivations and practices in small tourism enterprises in European protected areas. Journal of Cleaner Production, 137, 1439-1448.

Garay, L., \& Font, X. (2012). Doing good to do well? Corporate social responsibility reasons, practices and impacts in small and medium accommodation enterprises. International Journal of Hospitality Management, 31, 329-337.

Hall, C. M., Dayal, N., Majstorovic, D., Mills, H., Paul-Andrews, L., Wallace, C., \& Truong, V. D. (2016). Accommodation consumers and providers' attitudes, behaviours and practices for sustainability: A systematic review. Sustainability, 8(7).

Hobson, K., \& Essex, S. (2001). Sustainable tourism: A view from accommodation businesses. Service Industries Journal, 21(4), 133-146.

Kookana, J., \& Quinn, T. (2013). Tourism Businesses in Australia. Retrieved from Tourism Research Australia: 
https://www.tra.gov.au/ArticleDocuments/185/Tourism businesses 2016.pdf.aspx?Embed $=\underline{Y}$

Melissen, F. (2013). Sustainable hospitality: a meaningful notion? Journal of Sustainable Tourism, 21(6), 810-824.

Melisson, F., Koens, K., Brinkman, M., \& Smit, B. (2016). Sustainable development in the accommodation sector: A social dilemma perspective. Tourism Management Perspectives, 20, 141-150.

Morgan, D. L., Ataie, J., Carder, P., \& Hoffman, K. (2013). Introducing dyadic interviews as a method for collecting qualitative data. Qualitative Health Research, 23(9), 1276-1284.

Morrison, A., Carlsen, J., \& Weber, P. (2010). Small tourism business research change and evolution. International Journal of Tourism Research, 12, 739-749.

Patton, M. (2002). Qualitative Research and Evaluation Methods (3rd ed.). California: Sage Publications.

Thomas, R., Shaw, G., \& Page, S. J. (2011). Understanding small firms in tourism: A perspective on research trends and challenges. Tourism Management, 32, 963-976. 